
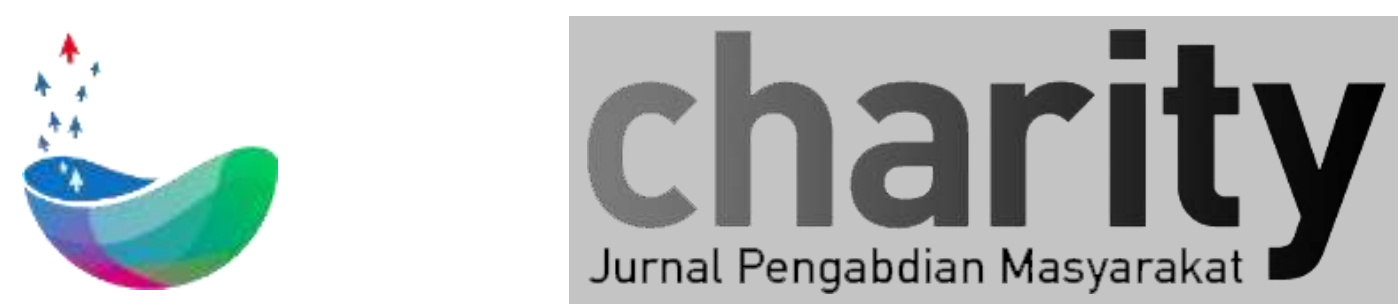

\title{
IMPELEMENTASI DAN PEMANFAATAN TEKNOLOGI UNTUK PROMOSI UNESCO GLOBAL GEOPARK CILETUH PALABUHANRATU SUKABUMI
}

Periyadi $^{1}$, Dewi K. Soedarsono ${ }^{2}$, Novian Denny Nugraha ${ }^{3}$, Uke kurniawan ${ }^{4}$, Nurwulan Fitriyanti ${ }^{5}$, Riksa Belasunda ${ }^{6}$, Diah Agung Esfandari

\footnotetext{
Teknologi Komputer, Fakultas Ilmu Terapan, Universitas Telkom

Ilmu komunikasi, Fakultas Komunikasi dan Bisnis, Universitas Telkom

Desain Komunikasi Visual, Fakultas Industri Kreatif, Universitas Telkom

${ }^{4}$ Teknik Telekomunikasi, Fakultas Teknik Elektro, Universitas Telkom

Teknik Fisika, Fakultas Teknik Elektro, Universitas Telkom

${ }^{6}$ Desain Komunikasi Visual, Fakultas Industri Kreatif, Universitas Telkom

Ilmu Komunikasi, Fakultas Komunikasi dan Bisnis, Universitas Telkom
}

\section{INFO ARTIKEL}

Diterima 15 Juli 2019

Direvisi 22 Juli 2019

Disetujui 30 Agustus 2019

Tersedia Online 09 September 2019

Keyword: UGG, Palabuhanratu, pariwisata, EGD, Geopark, komunikasi, system informas i guide, Geopark Information Center

\begin{abstract}
ABSTRAK
Kawasan pariwisata Unesco Global Geopark Ciletuh (UGG) Palabuhanratu merupakan manajemen pengelolaan kawasan yang menyerasikan keragaman geologi, hayati, dan budaya, melalui prinsip konservasi, edukasi, dan pembangunan yang berkelanjutan di 8 kecamatan di Sukabumi, 74 desa, luas \pm 126 hektar [1].

Sepanjang Geopark memiliki banyak destinasi wisata seperti : air terjun (curug), pantai, pegunungan, pulau, keanekaragaman biota hayati dan hewan, wisata budaya dengan kearifan lokal yang masih terjaga seperti adanya desa kasepuhan atau desa adat Sinar Resmi, Cipta Mulya, dan Cipta Gelar.

Geopark yang berada di sepanjang pantai selatan Sukabumi tersebut, merupakan salah satu geopark terpanjang di dunia, dan sedang diupayakan menjadi salah satu kawasan yang di akui oleh Unesco ; Untuk itu diperlukan sistem infrastruktur pariwisata yang terintegrasi dari aspek ekonomi, tekonologi, komunikasi, promosi dan sumber daya.

Dengan pendekatan pemberdayaan masyarakat ini diharapkan pariwisata dapat terbantu dengan dilakukan : Pengaplikasian sistem informasi guide berbasis deteksi lokasi, Pelatihan pemanfaatan media komunikasi sosial media untuk pariwisata, Perancangan Dan Perancangan Environtmental Graphic Design (EGD) Terpadu serta perancangan maskot pariwisata di Kabupaten Sukabumi.

Kegiatan tersebut akan dilakukan di Geopark Information Center yang melibatkan dinas pariwisata kabupaten sukabumi, pengelola Unesco Global Geopark, masyarakat setempat yang diundang, komunitas, dan pelajar sekolah . Hal ini dilakukan agar semua komponen yang telah disebutkan dapat berkontribusi dalam memajukan pariwisata di wilayah Unesco Global Geopark Ciletuh Palabuhanratu.
\end{abstract}

Korespondensi:

Direktorat Penelitian dan Pengabdian Masyarakat, Universitas Telkom

Jl. Telekomunikasi No. 1, Terusan Buah Batu, Bandung, 40257

Indonesia

E-mail : charity@telkomuniversity.ac.id 
ORCID ID: 0000-0002-1344-962X

Penulis Pertama: Periyadi

https://doi.org/10.25124/charity.v2i1.2133

Paper_reg_number 2133 @ The Authors. Published by Directorate of Research and Community Service, Telkom University.

This is an open access article under the CC BY-NC 4.0 license (https://creativecommons.org/licenses/ by-nc/4.0/)

\section{Pendahuluan}

Geopark atau taman dunia menjadi konsep wisata baru yang saat ini tengah dikembangkan Kementerian Pariwisata. Konsep geopark ini diperkenalkan pertama kali oleh UNESCO pada tahun 2000. Konsep geopark mengacu pada pengembangan kawasan yang memberikan pengaruh terhadap konservasi, pendidikan, dan peningkatan taraf hidup/kesejahteraan masyarakat. Geopark merupakan konsep manajemen pengembangan kawasan/wilayah berkelanjutan yang mengharmoniskan keragaman geologi, flora, fauna, dan budaya melalui prinsip konservasi dan rencana tata ruang wilayah yang sudah ada.

Geopark yang dikenal dengan Unesco Global Geopark (UGG), terletak di barat daya Kabupaten Sukabumi memiliki luas 126.100 ha $(1.261 \mathrm{~km} 2)$ meliputi 74 desa di 8 kecamatan yaitu Ciracap, Surade, Ciemas, Waluran, Simpenan, Pelabuhan Ratu, Cikakak, dan Cisolok, yang terbagi dalam tiga Geoarea yakni Geoarea Simpenan, Geoarea Cisolok, dan Geoarea Ciletuh, serta berbentuk amfiteater (bentang alam setengah lingkaran) berdiameter seluas $15 \mathrm{~km}$. Geopark Nasional Ciletuh diakui PBB bidang pendidikan budaya (UNESCO) per 22 Desember 2015 dan diresmikan menjadi Geopark Nasional Ciletuh-Pelabuhan Ratu per 21 Juni 2016.

Kabupaten Sukabumi adalah wilayah yang memiliki 102 desa tertinggal dari total 381 desa yang tersebar di 47 kecamatan, di antaranya empat desa tertinggal yang berlokasi di kecamatan kawasan geopark seperti Desa Cirendang di Kecamatan Cikakak, Desa Gunung Tanjung, Desa Sukarame dan Desa Wanajaya di Kecamatan Cisolok. Keseluruhan desa tertinggal ditunjukkan pada gambar 1.

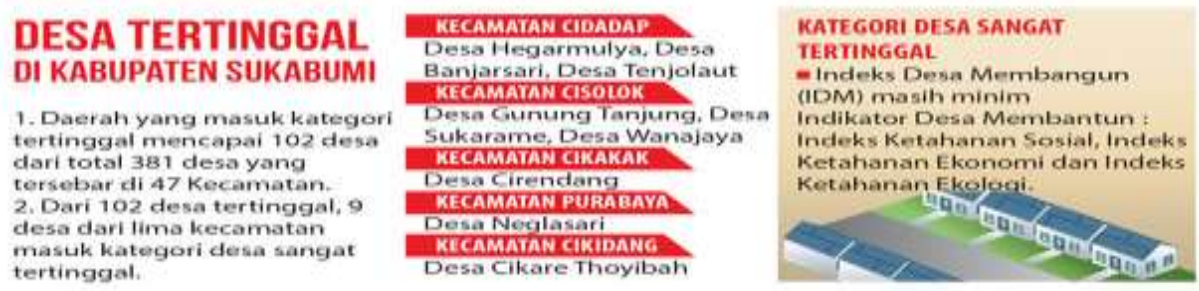

Gambar 1 Desa Tertinggal di Kabupaten Sukabumi

(Sumber: http://radarsukabumi.com/kabsukabumi/tag/desa-tertinggal diakses 21-4-2017 )

Dalam pandangan wisata, kawasan geopark Ciletuh memiliki keunikan yang dapat dijual sebagai salah satu destinasi wisata Indonesia. Geopark terbentuk dari hasil tumbukan lempeng 60 juta tahun silam dan merupakan daratan pertama di Jawa Barat. Wilayah ini menawarkan sejumlah potensi wisata unggulan yang belum maksimal dieksplorasi dan dipetakan. Destinasi wisata mencakup air terjun, pemandangan yang indah, hingga wisata laut. Salah satu contoh destinasi yang belum dikelola dengan maksimal adalah Curug Sodong, di mana posisi air terjun tersebut tersembunyi berada di balik cekungan sebuah bukit. Airnya segar dan berasal dari perkebunan teh Ciemas. Ketika sedang musim kemarau, debit air di air terjun ini tidak banyak, bentuk air terjunnya serupa tirai yang tipis. 
Kawasan Unesco Global Geopark (UGG) Ciletuh Palabuhanratu merupakan wilayah geografis yang mempunyai situs warisan geologi dan bagian dari konsep komprehensif perlindungan, pendidikan dan pembangunan berkelanjutan Kabupaten Sukabumi. Peran serta masyarakat yang tinggal dalam kawasan ini untuk turut melindungi dan meningkatkan fungsi warisan alam.

Pembangunan dan pertumbuhan perekonomian pada wilayah geopark dengan mengembangkan paket pariwisata meliputi: ekowisata, geowisata, wisata buatan manusia, wisata bahari, wisata petualangan, wisata kuliner, wisata budaya, dan wisata belanja. Usaha untuk mewujudkannya perlu dukungan regulasi dan kebijakan pemerintah, infrastruktur, fasilitas, pemberdayaan masyarakat, serta kerjasama strategis antara pemerintah, komunitas, badan usaha/pengusaha, media, dan akademisi (sivitas akademika sekolah dan perguruan tinggi). Kerjasama strategis ini disebut pentahelix. Kerja sama ini belum sepenuhnya terjalin, oleh karenanya masih dibutuhkan masukan untuk pengelolaan komunikasi pariwisata di wilayah Geopark Ciletuh.

Unesco Global Geopark (UGG) Ciletuh Palabuhanratu memiliki semboyan "Memuliakan bumi, mensejahterakan masyarakat". Semboyan ini menunjukkan bahwa wisata alam menjadi fokus utama pariwisata di daerah Geopark ini.

Data menunjukkan bahwa angka kunjungan dari tahun ke tahun meningkat. Kenaikan data tersebut masih didominasi oleh kunjungan wisatawan domestik. Berikut data kunjungan sejak tahun 2012 hingga 2016.

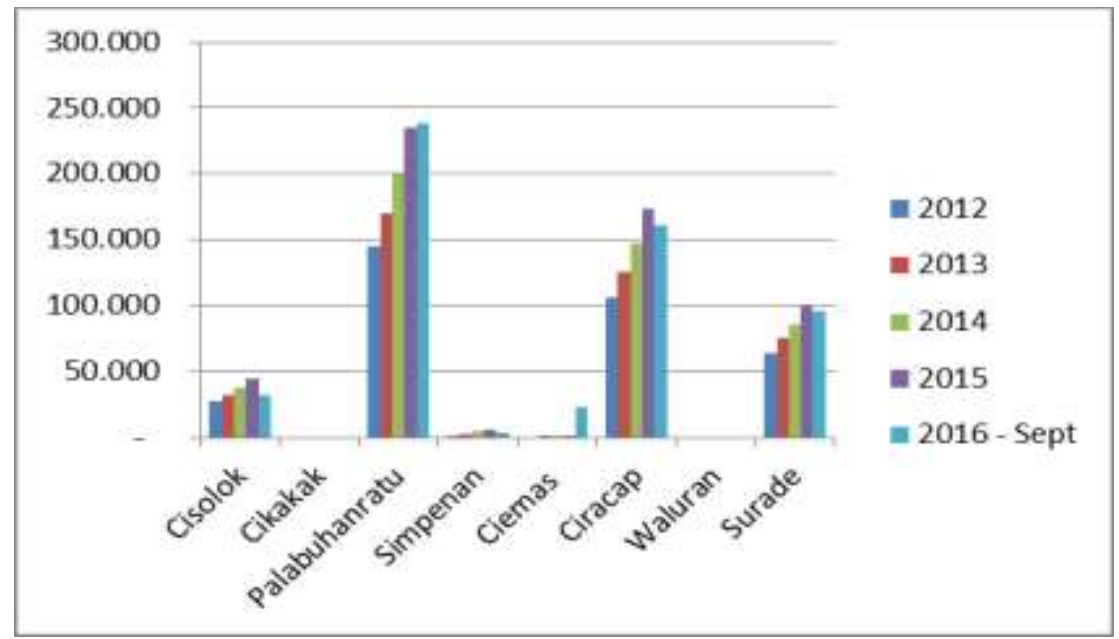

Gambar 0.1 Kunjungan wisatawan per tahun

(sumber: Disbudpar Kabupaten Sukabumi)

Data di atas menunjukkan bahwa belum sepenuhnya wilayah Geopark Ciletuh ini mendapat kunjungan wisatawan. Berdasarkan pemaparan dan hasil pengamatan lapangan, ketidakmerataan ini disebabkan beberapa hal, pertama karena minimnya informasi mengenai Geopark Ciletuh, kedua karena sarana dan prasarana yang masih seadanya dan kurang perawatan. Ketiga, minimnya kesadaran masyarakat mengenai dukungan mereka terhadap wisata geopark.

Geopark adalah sebuah konsep manajemen pengembangan kawasan berkelanjutan yang menyerasikan keragaman geologi, hayati, dan budaya melalui prinsip konservasi dan Rencana Tata Ruang Wilayah yang sudah ada; sehingga diperlukan sistem manajemen yang mampu mensinergikan aspek-aspek yang terdapat dalam kawasan tersebut agar terintegrasi sebagai destinasi wisata yang 
menarik. Newsome and Dowling (2010) dalam penelitian Andriyani, Fatimah dan Hardiyono (2016:76) menyatakan bahwa geowisata meliputi beberpa aspek berikut:

a. Geo-site sightseeing

Berekreasi atau bertamasya dengan menikmati landscape dari keunikan bentukan kebumian.

b. Geo-sport

Olahraga yang berhubungan dengan topografi bumi.

c. Geo-study

Kegiatan studi di alam terbuka, termasuk observasi warisan geologi, fotografi geo-lanskap, kunjungan lapangan untuk kepentingan geologi.

d. Geo-konservasi dan Geo-pendidikan

Program konservasi terhadap potensi kebumian untuk kepentingan edukasi atau pelestarian.

e. Geo-festival

Event yang dibuat untuk keberlangsungan sumber geologi atau wadah promosi terhadap bentuk program konservasi.

f. Fasilitas Geo-tours

Bentuk interpretasi mandiri (peta geowisata) ataupun fasilitas pemandu wisatawan.

g. Health and Wellness geotourism

Bentuk fasilitas kesehatan ataupun relaksasi seperti terapi spa, terapi batu, dan terapi lumpur.

Dalam pelaksanaan pengelolaan pariwisata masyarakat sebagai agen perubahan di wilayah Unesco Global Geopark perlu diberi pengetahuan akan kondisi keindahan alam disekitar daerah wisata. Melalui pemberdayaan masyarakat yang dilakukan dengan memanfaatan sistem informasi terpadu, pendekatan media komunikasi dan Pengembangan Environmental Graphic Design ( EGD ) sebagai alat bantu menginformasikan kondisi pariwisata di kawasan Unesco Global Geopark (UGG) Ciletuh Palabuhanratu.

\section{Masalah}

Permasalahan yang ditemukan selama proses survey ke lokasi dalam pelaksanaan pengabdian masyarakat ini adalah :

1. Masih belum maksimal pemberitaan dan informasi pengembangan aspek pariwisata dari sisi promosi serta kegiatan apa saja yang ada di wilayah Unesco Global Geopark Ciletuh Palabuhanratu (UGG)

2. Mengacu pada salah satu standar yang berikan oleh Unesco, bahwasanya pusat informasi Geopark harus mampu menampilkan system yang bersifat interaktif, sekaligus masih kurangnya informasi yang dapat diberikan oleh staff kantor informasi terhadap pengujung karena keterbatasan jumlah staff yang ada di kantor Geopark Information Center

3. Belum ada standar dan keseragaman papan penunjuk informasi diseluruh Kawasan Unesco Global Geopark Ciletuh Palabuhanratu.

4. Belum adanya maskot/ikon pariwisata yang dimiliki oleh pemerintah kabupaten sukabumi. 


\section{Metoda Pelaksanaan}

\subsection{Metode Pelaksanaan Kegiatan Pengabdian}

Pengabdian Masyarakat yang akan dilaksanakan di Dinas Pariwisata Kabupate Sukabumi dan Kantor Geopark Information Center.

Adapun metode yang dilakukan dalam pelaksanaan pengabdian masyarakat ini ini adalah dengan melakukan edukasi para penggiat pariwisata dan staff Geopark Information Center dalam bentuk petani dalam bentuk pelatihan-pelatihan yang diakukan di dua lokasi berbeda, yaitu Kantor Geopark Information Center dan Kantor Dinas Pariwisata Kabupaten Sukabumi.

Sedangkan untuk usulan rancangan Environmental Graphic Design(EGD) dan Maskot pariwisata kabupaten Sukabumi di presentasikan kepada staff dinas pariwisata Kabupaten Sukabumi dan staff Geopark Information Center.

Kegiatan yang dilakukan dibagi kedalam 3 kegiatan :

1. Memberikan pelatihan tentang pemanfaat media sosial untuk promosi Unesco Global Geopark

2. Menerapkan teknologi tepat guna system dan aplikasi guide berbasis deteksi lokasi

3. Merancang Environmental Graphic Design(EGD) dan Maskot pariwisata kabupaten Sukabumi

Adapun peserta kegiatan terdiri dari :

1. Siswa SMA, yang diwakili oleh siswa SMA dan SMK Mutiara Terpadu Palabuhanratu

2. Staff dinas Pariwisata Kabupaten Sukabumi

3. Penggiat pariwisata Kawasan Unesco Global Geopark, Sukabumi face, POKMASI, Desa Wisata Hanjeli, PAPSI

4. Staff Geopark Information Center

\subsection{Teknik Pengumpulan data}

Pengumpulan data dilakukan dengan teknik pengambilan data berupa pertanyaan kuesioner dan observasi. Ini dilakukan untuk melengkapi data permulaan tentang masayarakat sasar dan kebutuhan yang dibutuhkan masyarakat sasar dalam kegiatan pengabdian masyarakat ini. Keusioner diberikan pada saat acara kegiatan di atas dilakukan digunakan sebagai alat ukur seberapa besar respon yang diberikan oleh masyarakat sasar terhadap kegiatan pengabdian yang dilakukan.

\subsection{Teknik Analisis}

Kegiatan pengabdian ini merupakan penerapan dari hasil riset yang sudah dilakukan sebelumnya. Untuk penerapan sistem guide berbasis deteksi lokasi, proses yang dilakukan di lokasi adalah dengan melakukan klastering data konten yang disesuaikan dengan kebutuhan di kantor Geopark Information Center. Tujuannya adalah agar setiap informasi yang disamaikan sesuai dengan tematik ruangan yang ada di kantor Geopark Information Center (GIC). 


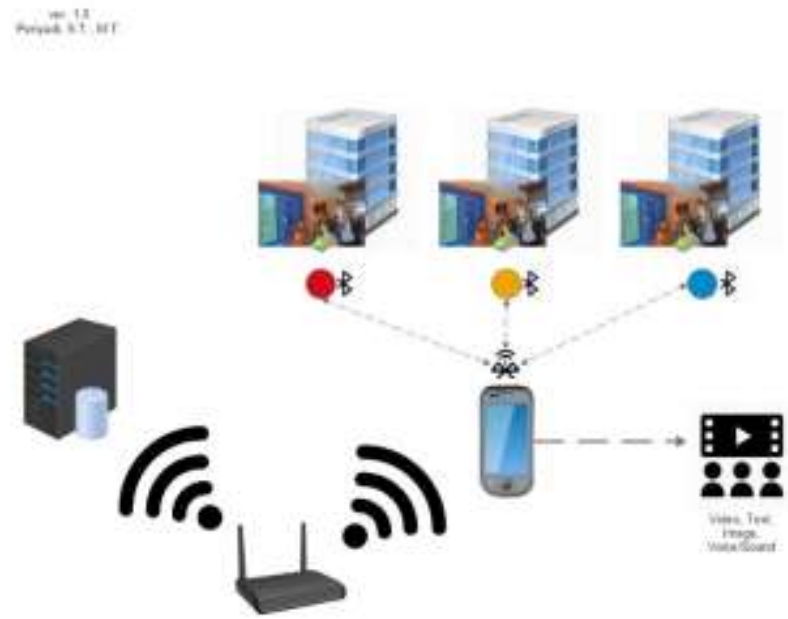

Gambar 2 Infrastruktursistem guide berbasis deteksi lokasi

Untuk perancangan Environmental Graphic Design (EGD) proses analisisnya dengan memperhatikan aspek kearifan local dengan melakukan pendekatan perancangan konsep Design Thinking Process seperti pada gambar 3. Konsep ini merupakan metodologi desain yang memberikan pendekatan berbasis solusi untuk menyelesaikan masalah. Konsep ini di gunakan untuk mengatasi masalah kompleks dengan memahami kebutuhan pengguna yang terlibat, dengan merangkai ulang masalah, dengan cara yang berpusat pada pengguna itu sendiri, dengan menciptakan banyak ide dalam sesi brainstorming, dan dengan mengadopsi pendekatan langsung dalam pembuatan ide prototipe dan pengujian. Proses ini menghasilkan rancangan Environtmental Graphic Design (EGC) dan maskot pariwisata untuk kawasan Unesco Global Geopark (UGG) Ciletuh Palabuhanratu.

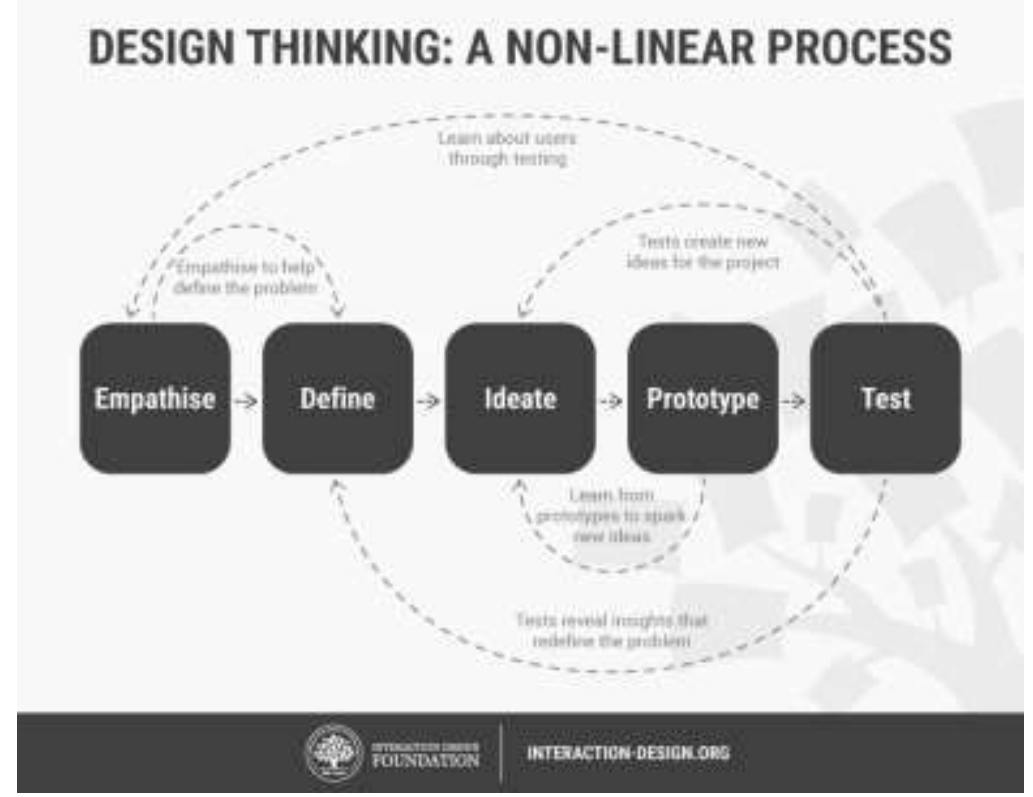

Gambar 3 Konsep Design Thinking Process [2] 


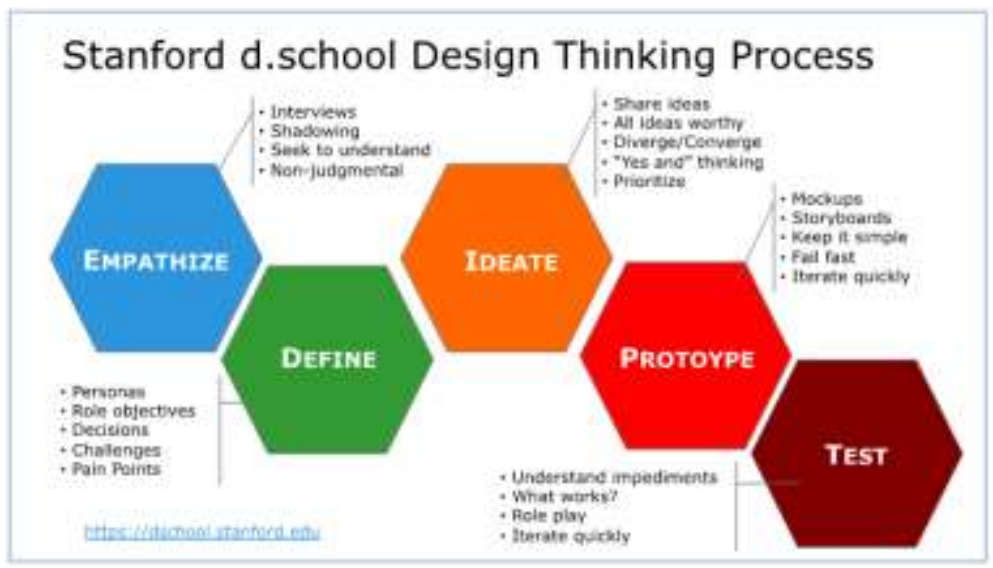

Gambar 4 Lima tahap Design Thinking [3]

3.4. Lokasi, Waktu, dan Durasi Kegiatan

Kegiatan akan dilaksanakan di dua lokasi yaitu :

1. Aula Kantor Dinas Pariwisata Kabupaten Sukabumi, Jl. Komp. Perkantoran Jajaway, Citepus, Pelabuhan Ratu, Sukabumi, Jawa Barat 43364

2. Kantor Geopark Information Center, Jl. Raya Citepus KM. 3 No. 32, Citepus, Pelabuhan Ratu, Citepus, Pelabuhan Ratu, Sukabumi, Jawa Barat 43364

\section{Analisa Hasil Kegiatan Pengabdian Masyarakat}

Pengabdian masyarakat merupakan suatu kegiatan yang bertujuan membantu masyarakat tertentu dalam beberapa aktivitas tanpa mengharapkan imbalan dalam bentuk apapun. Secara umum program ini adalah bagian dari Tri Dharma Perguruan Tinggi.

Universitas Telkom merupakan salah satu univeritas yang juga melakukan kegiatan ini dalam beberapa skema, yang diarahkan untuk pendekatan masyarakat sasar seperti ;

1. Masyarakat Dunia Usaha (kecil, menengah).

2. Masyarakat di Instansi Pemerintah.

3. Perorangan atau Kelompok Masyarakat (tidak/kurang produktif).

Unit Layanan Masyarakat (Non-Profit).

Kegiatan pengabdian yang dilakukan oleh tim ini menggunakan skema kolaborasi internal, dengan melibatkan beberapa kelompok keahlian dan fakultas serta program studi yang berbeda. Dalam pelaksanaannya sendiri masing-masing melakukan kajian terkait dengan masyarakat sasar yang akan di tuju. Pendekatan kajian awal ini yang pada akhirnya menghasilkan beberapa sub tema kegiatan yang disesuaikan dengan kebutuhan masyarakat sasar yang akan diberikan pengabdian masyarakat.

Kegiatan pertama adalah memberikan materi pelatihan Pemanfaatan media komunikasi social media untuk pariwisata, kegiatan kedua adalah memberikan hibah alat serta pelatihan penggunaan alat, kegiatan ketiga adalah memberikan usulan rancangan EGD dan maskot pariwisata Kabupaten Sukabumi. 
Kegiatan pelatihan direncanakan akan diadakan di Aula Dinas Pariwisata Kabupaten sukabumi dan Kantor Geopark Information Center dengan peserta :

1. Siswa SMA Mutiara Terpadu Palabuhanratu

2. Siswa SMK Mutiara Terpadu Palabuhanratu

3. Komunitas penggiat pariwisata Kabupaten Sukabumi (sukabumi face, pokmasi, Desa wisata hanjeli, papsi)

4. Staff dinas pariwisata Kabupaten Sukabumi

5. Staff Geopark Information Center

Bentuk aktifitas pengabdian masyarakat terkait kegiatan yang dilakukan di atas dapat di lihat pada gambar

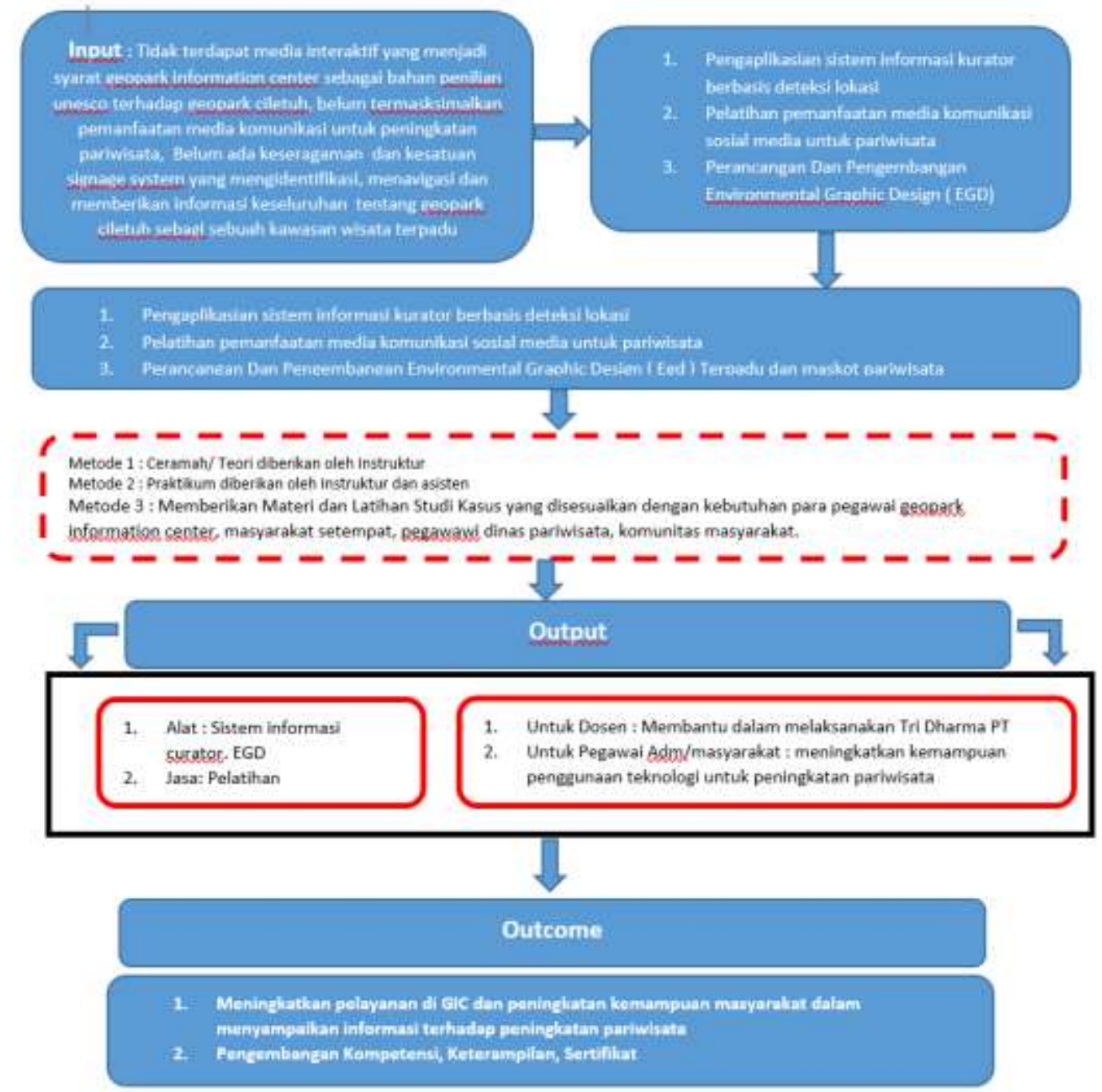

Gambar 5 Gambar Ilmu Pengetahuan dan Teknologi yang ditransfer ke masyarakat sasar 


\section{Kesimpulan dan Saran}

Pelaksanakan pembangunan prasarana wisata diperlukan koordinasi yang baik antara instansi terkait bersama dengan instansi pariwisata di berbagai tingkat. Dukungan instansi terkait dalam membangun prasarana wisata sangat diperlukan bagi pengembangan pariwisata di daerah khususnya di kabupaten sukabumi yang memiliki Kawasan Unesco Global Geopark Ciletuh palabuhanratu. Pemerintah Kabupaten Sukabumi dalam hal ini Dinas Pariwisata meyakini hal tersebut, sehingga diperlukan kualitas sumber daya manusia serta sarana dan prasarana yang mendukung peningkatan pariwisata khususnya Kawasan Unesco Global Geopark Ciletuh palabuhanratu. Kegiatan pengabdian masyarakat ini diyakini menjadi salah satu daya dorong kearah tersebut. Hal ini di pertegas dengan hasil kuesioner yang di peroleh dari hasil kegiatan yang menunjukan kebermanfaatan kegiatan ini. Ketiga kegiatan ini berhasil dilakukan dan mendapatkan respon cukup positif karena selain dapat membantu pengembangan informasi sekaligus menambah wawasan dan meningkatakan nilai tambah dari Kantor Pusat Informasi Unesco Global Geopark Ciletuh Palabuhanratu. Sesuai dengan range skor feedback kegiatan 98.33\% menyatakan sangat bermanfaatnya kegiatan ini.

Pengabdian masyarakat yang dilakukan telah diterima oleh pihak masyarakat sasar dan dianggap membantu pihak terkait khususnya Dinas Pariwisata Kabupaten Sukabumi sehingga, output yang dihasilkan dari kegiatan pegabdian masyarakat ini dapat :

1. Menambah wawasan penggiat pariwisata di lingkungan Unesco Global Geopark Ciletuh Palabuhanratu

2. Dapat menyelesaikan masalah penanganan kuantitas jumlah pengunjung yang tertangani untu kmemperoleh informasi seputar lokasi dan informasi wisata di gugus Unesco Global Geopark dengan memanfaatkan system informasi guide berbasis lokasi yang dipasang di 3 buah ruangan di kantor Geopark Information Center

3. Menambah masukan untuk rencana pengembangan Environtmental Graphic Design (EGD).

4. Merencanakan maskot pariwisata untuk di jadikan icon resmi pariwisata Kabupaten Sukabumi sekaligus rencana mengajukan paten/Hak cipta terhadap maskot yang sudah dirancang.

Masukan untuk kedepan adalah tetap secara berakala ada pemantauan terhadap semua kegiatan yang sidah dilakukan agar tetap berlangsung dengan baik. 


\section{DAFTAR PUSTAKA}

[1] B. P. Geopark, "ciletuh palabuhanratu geopark," [Online]. Available: http://ciletuhpalabuhanratugeopark.org/. [Accessed 286 2019].

[2] "https://www.interaction-design.org/," interaction-design.org, [Online]. Available: https://think360studio.com/what-is-design-thinking-and-design-thinking-process/. [Accessed 37 2019].

[3] Badan Pusat Statistik, "Indeks Pembangunan Manusia menurut Kabupaten/Kota, 2016 (mentode Baru)," 2017. [Online]. Available: https://www.bps.go.id/subjek/view/id/26\#subjekViewTab3 . [Accessed 6 November 2017].

[4] B. P. S. K. Sukabumi, "Kecamatan Palabuhanratu dalam Angka 2017," 2017. [Online]. Available:

https://sukabumikab.bps.go.id/index.php/publikasi/index?Publikasi\%5BtahunJudul\% $5 \mathrm{D}=\&$ Publikasi\%5BkataKunci\%5D=ratu\&yt0=Tampilkan . [Accessed 6 November 2017]. 
Lampiran Kegiatan

1. Video Kegiatan

https://www.youtube.com/watch?v=MvipcTQrkHg\&t=2s

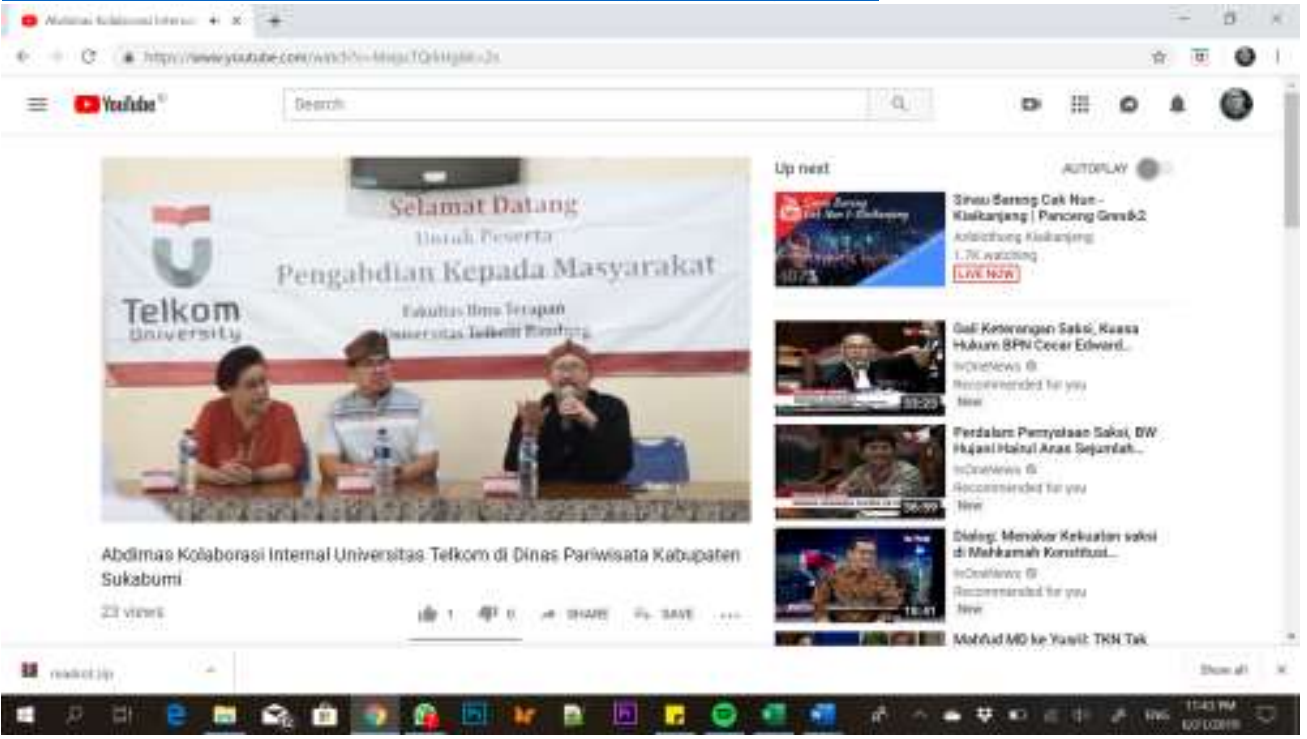

2. Foto Kegiatan

\begin{tabular}{|c|c|}
\hline the shin 02:26 $\mathrm{sin} \cdots$ & 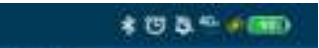 \\
\hline \multicolumn{2}{|c|}{$\begin{array}{l}\text { Sistem Pemandu Galeri } \\
\text { Jumlah Galeri: } 6\end{array}$} \\
\hline $\begin{array}{c}\text { GEOLOGI } \\
\text { Ditatance:0.652m }\end{array}$ & 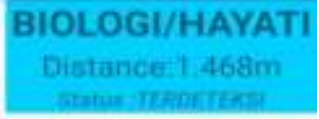 \\
\hline 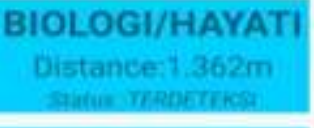 & $\begin{array}{c}\text { BIOLOGI/HAYATI } \\
\text { Distance } 0.588 m \\
\text { statuin reagernksi }\end{array}$ \\
\hline 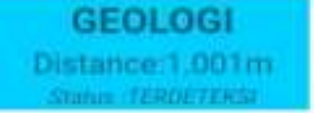 & $\begin{array}{c}\text { GEOLOGI } \\
\text { Distance } 0.514 \mathrm{~m}\end{array}$ \\
\hline
\end{tabular}
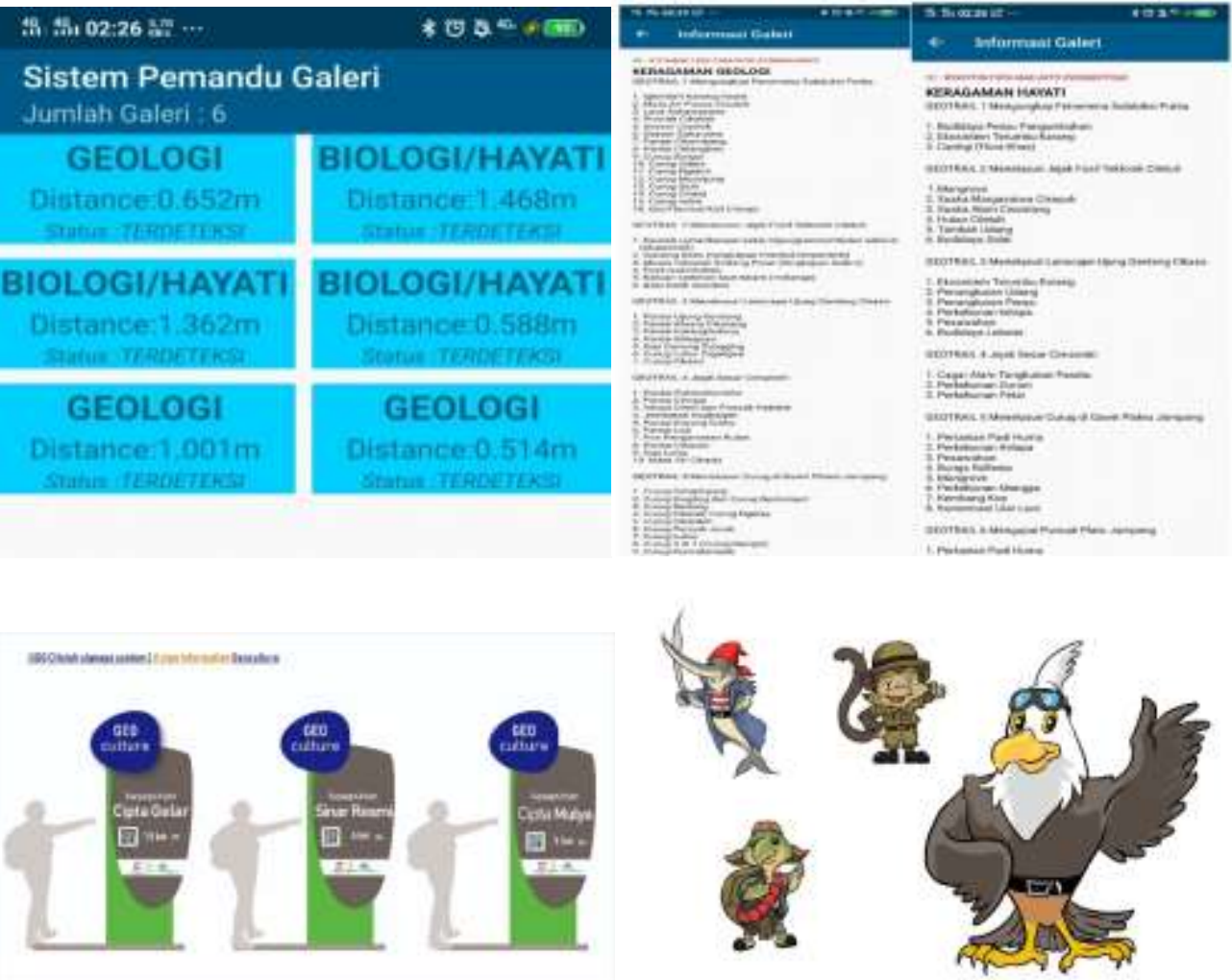


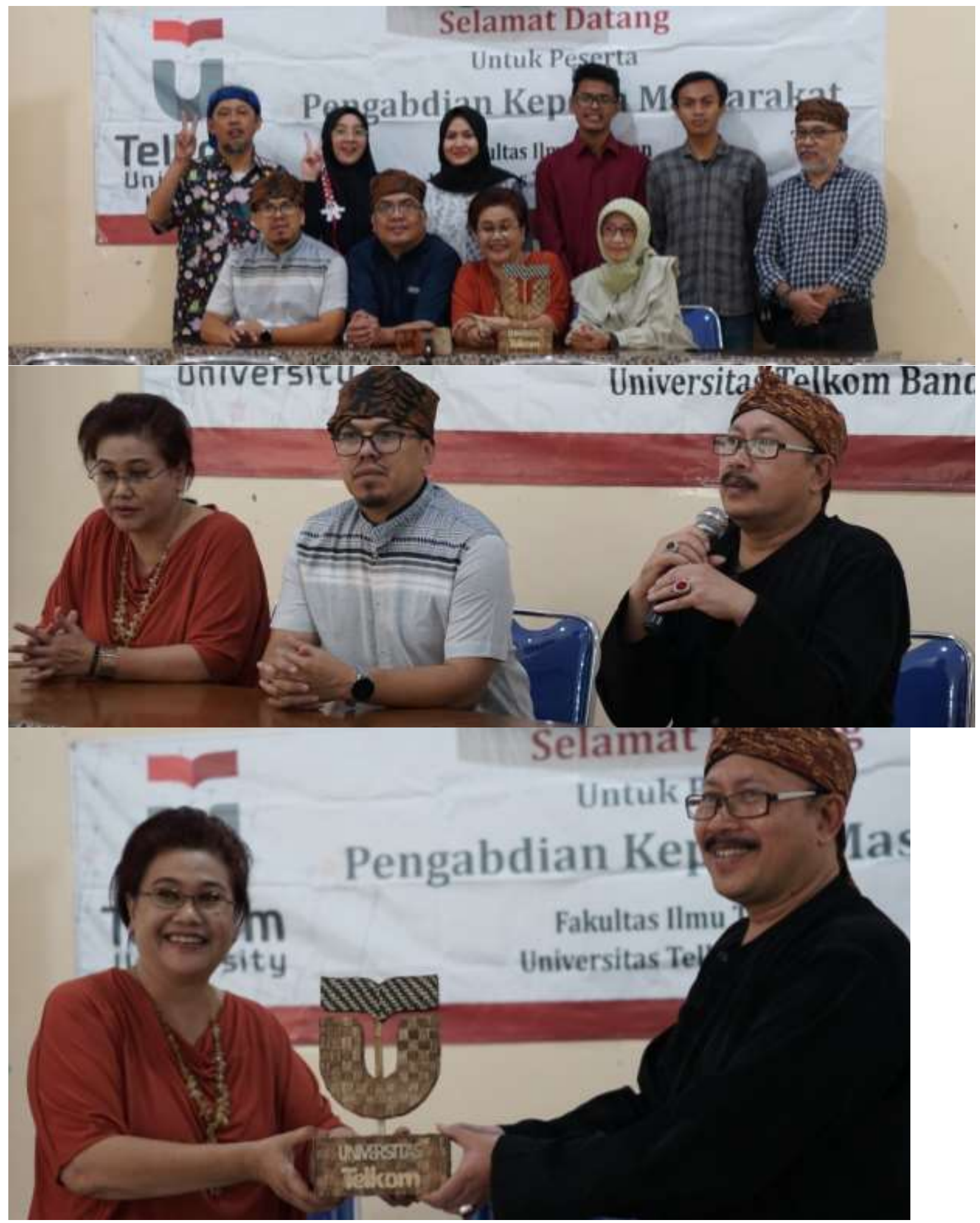




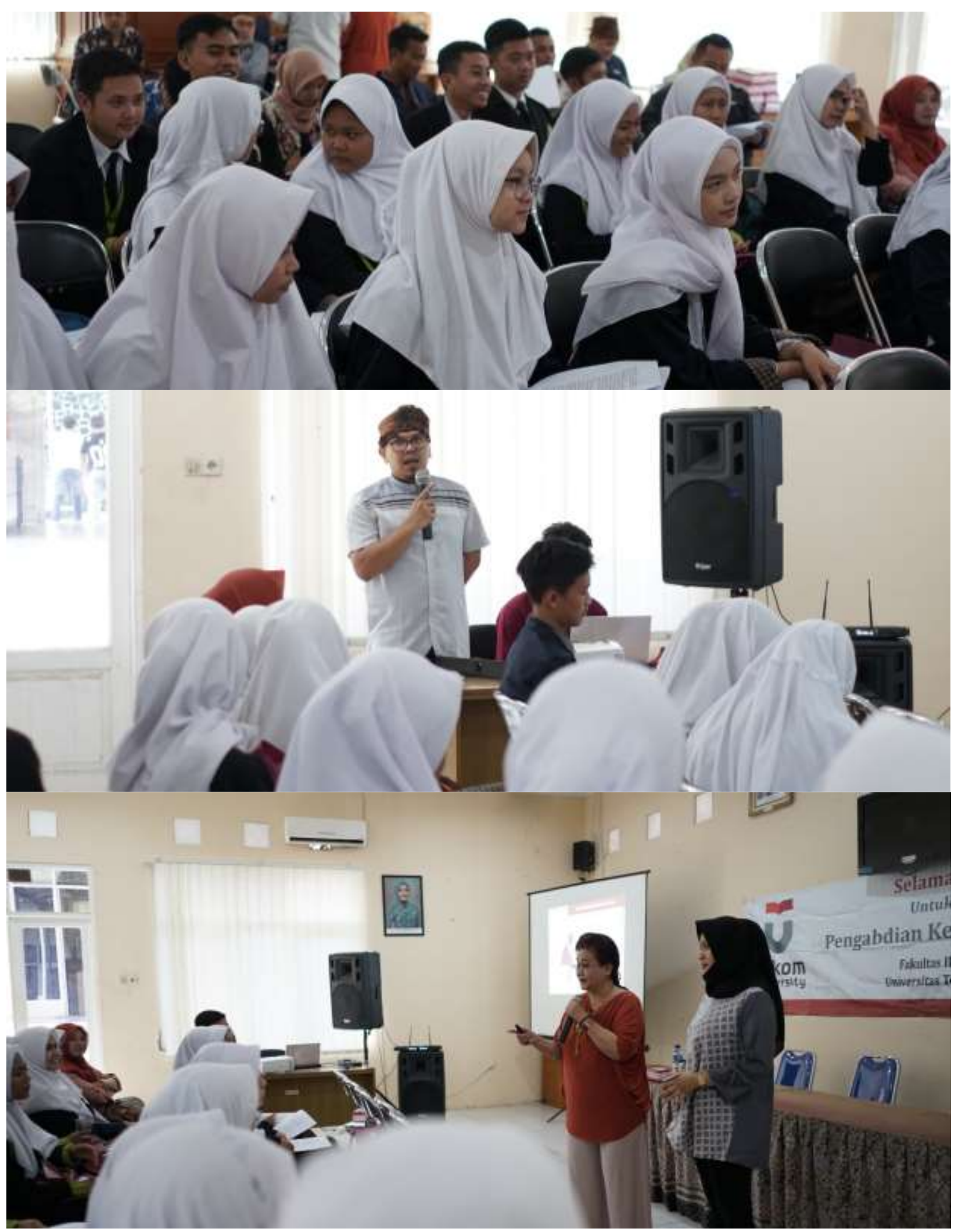




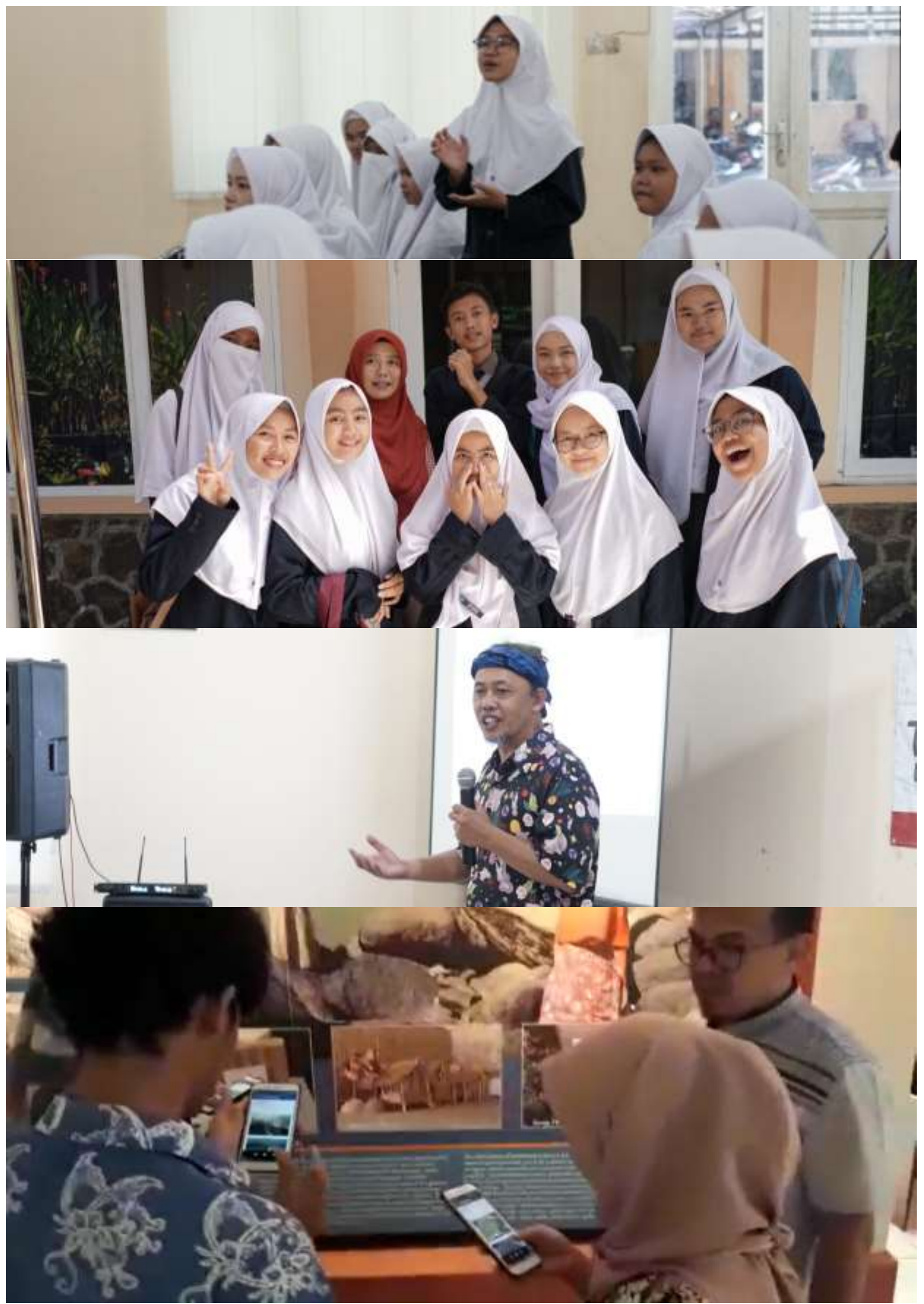

